\title{
Advice given by community members to pregnant women: a mixed methods study
}

Bianca A. Verma ${ }^{1}$, Lauren P. Nichols ${ }^{2}$, Melissa A. Plegue ${ }^{2}$, Michelle H. Moniz ${ }^{3,5}$, Manisha Rai ${ }^{4}$ and Tammy Chang ${ }^{2,5^{*}}$ (i)

\begin{abstract}
Background: Smoking and excess weight gain during pregnancy have been shown to have serious health consequences for both mothers and their infants. Advice from friends and family on these topics influences pregnant women's behaviors. The purpose of our study was to compare the advice that community members give pregnant women about smoking versus the advice they give about pregnancy weight gain.

Methods: A survey was sent via text messaging to adults in a diverse, low-income primary care clinic in 2015. Respondents were asked what advice (if any) they have given pregnant women about smoking or gestational weight gain and their comfort-level discussing the topics. Descriptive statistics were used to characterize the sample population and to determine response rates. Open-ended responses were analyzed qualitatively using grounded theory analysis with an overall convergent parallel mixed methods design.
\end{abstract}

Results: Respondents $(n=370)$ were $77 \%$ female, $40 \%$ black, and $25 \%$ reported education of high school or less. More respondents had spoken to pregnant women about smoking (40\%,n=147) than weight gain $(20 \%, n=73)$. Among individuals who had not discussed either topic $(n=181)$, more reported discomfort in talking about weight gain $(65 \%)$ compared to smoking (34\%; $p<0.0001)$. Advice about smoking during pregnancy $(n=148)$ was frequently negative, recommending abstinence and identifying smoking as harmful for baby and/or mother. Advice about weight gain in pregnancy $(n=74)$ revealed a breadth of messages, from reassurance about all weight gain ("Eat away" or "It's ok if you are gaining weight"), to specific warnings against excess weight gain ("Too much was dangerous for her and the baby.").

(Continued on next page)

\footnotetext{
* Correspondence: tachang@med.umich.edu

2Department of Family Medicine, University of Michigan, 1018 Fuller Street, Ann Arbor, Ml 48104, USA

${ }^{5}$ Institute for Healthcare Policy and Innovation, University of Michigan, 2800 Plymouth Road, North Campus Research Complex, Building 16, Ann Arbor, Ml 48109, USA

Full list of author information is available at the end of the article
} 
(Continued from previous page)

Conclusions: Many community members give advice to pregnant women. Their advice reveals varied perspectives on the effects of pregnancy weight gain. Compared to a nearly ubiquitous understanding of the harms of smoking during pregnancy, community members demonstrated less awareness of and willingness to discuss the harms of excessive weight gain. Beyond educating pregnant women, community-level interventions may also be important to ensure that the information pregnant women receive supports healthy behaviors and promotes the long-term health of both moms and babies.

Keywords: Advice, Friends, Family, Pregnancy, Weight gain, Community health, Smoking

\section{Background}

Health behaviors, such as smoking, physical activity, and dietary habits, have a critical impact on obstetric and neonatal outcomes [1]. Smoking in pregnancy is associated with low birth weight, preterm birth stillbirth and placental abruption, while excess weight gain in pregnancy is associated with hypertensive disorders of pregnancy, gestational diabetes, excessive fetal growth, prolonged labor, birth injury, and cesarean delivery [2-5]. Furthermore, excess weight gain in pregnancy may be associated with an increased risk of long-term obesity in both mother and child [6-9].

Pregnant women receive information about weight gain from several sources, including clinicians, the Internet, and family and friends $[10,11]$. There is variability in the consistency with which clinicians discuss appropriate weight gain with their pregnant patients: studies report that between 12 and $85 \%$ of pregnant women were counseled correctly by their healthcare provider regarding how much they should gain during pregnancy $[12,13]$. Clinicians may be reluctant to discuss the sensitive topic of weight gain with their overweight or obese patients $[12,14,15]$. Additionally, the Internet is a common source of health information among pregnant women with nearly all women (94\%) using the Internet for pregnancy-related information [16-18]. However, one recent study concluded that the most frequently visited webpages on gestational weight gain do not provide accurate and complete information compared to the 2009 Institute of Medicine guidelines for gestational weight gain $[19,20]$.

Many pregnant women report that the opinions of friends and family influence their weight gain during pregnancy even more than clinicians or the internet [21, 22]. Several models for understanding the effects of interpersonal support demonstrate that information and advice given by family and friends has a unique influence on behavior change because it is within the context of a caring and trusting relationship [23]. Additionally, social supports can facilitate the coping process and mitigate the effects of health stressors, which may explain why women may seek support from friends and family during a pregnancy [24].
Despite the importance of friend and family advice on women's behavior, few studies have characterized the frequency or content of this advice, and even fewer have directly asked family and friends about their opinions of these behaviors. These studies suggest that the friends and family of low-income, African American pregnant women are likely to encourage "eating for two," without acknowledging the dangers of too much weight gain, or acknowledging the different recommendations for weight gain depending on pre-pregnancy BMI $[11,25]$. One study found that pregnant women believe that weight gain during pregnancy is uniformly vital for having a healthy baby [26].

Health behaviors during pregnancy are influenced by advice from non-medical sources, yet remain poorly characterized in the medical literature [27-31]. The American public's increasing recognition of the risks of smoking have created social norms that discourage smoking, however similar social norms to discourage excessive gestational weight gain are not well understood [32-34]. The objective of this study was to determine retrospectively whether community members give advice to pregnant women, what advice they give about smoking versus weight gain during pregnancy, and to assess their comfort in speaking about these topics.

\section{Methods \\ Sample}

The University of Michigan Institutional Review Board reviewed this study and determined that it was exempt from review as all survey data collected was anonymous. A sample of adults was recruited from a waiting room of an academic primary care clinic in a low-income community. All visitors who were 18 years or older and owned cell phones with text messaging capability were eligible and were asked when entering the waiting room if they were interested in participating. Pregnant females were excluded from analyses given the possibility of social desirability bias. Recruitment was conducted from June through August of 2015. 


\section{Survey instrument and administration}

The investigators developed a survey with 51 unique questions (Appendix 1). The survey was distributed via text messaging. Text messaging is used across nearly all age and income groups, and has been shown to be a cost-effective and preferred form of data collection among low-income populations over traditional techniques such as paper, online, and phone surveys [35, 36].

A subset of the survey questions will be described in this study. The survey employed branching logic so that an individual respondent was asked between 17 and 30 questions. The first six questions asked respondents to report their unique survey access code, age, race, education level, phone type, and gender. Survey domains included healthy habits during pregnancy, gestational weight gain, use of preventive care services, and insurance coverage.

Multiple choice and free text questions were asked. Free text questions accepted any answer as valid. Multiple choice questions restricted responses that fell outside the parameters of a valid answer (i.e. answering anything other than yes/no/not sure to "Are you pregnant now?"), which prompted the survey to respond with "Sorry, we do not recognize that answer. Please try again." Respondents could skip any question by typing the word "skip."

\section{Recruitment and data collection}

The study staff member asked individuals in the waiting room if they were interested in participating in the study. If the participant responded affirmatively, the recruiter gave him/her a flyer (with the token gift: chapstick or frisbee) and explained how to complete the survey. Participants were encouraged to ask the recruiter any questions or for help with technical difficulties. Participants were able to complete the survey at any location, whether in the waiting room, doctor's office, or outside the clinic setting. Survey responses were stored and transmitted by Mosio.com, a secure online texting platform.

\section{Analysis}

Descriptive statistics were calculated for demographic information and the responses to each of the following close-ended questions: "Have you ever spoken with a pregnant woman about smoking during pregnancy?" and "'Have you ever spoken with a pregnant woman about weight gain during pregnancy?" McNemar's test was used to compare the proportion of respondents who had spoken about smoking with those who had spoken about weight gain. Respondents who reported that they have never spoken about these topics before were asked, "Would you feel comfortable talking about this topic with a pregnant woman?" McNemar's test was also used to compare the proportion that felt comfortable versus those that did not feel comfortable. Logistic regression was used to characterize the groups of individuals who had only spoken about smoking, only spoken about weight gain and those who reported speaking about both.

Respondents who reported speaking to a pregnant woman about either smoking or pregnancy were then asked one of two open-ended questions: "What did you say to her [pregnant woman] about smoking during pregnancy?" or "What did you say to her [pregnant woman] about weight gain during pregnancy?" respectively. The responses to these open-ended responses were analyzed qualitatively using a grounded theory approach. Two researchers (BV and LN) simultaneously, but independently, identified themes and created preliminary codes. Then through an iterative process to reach consensus, a codebook was created that encompassed both the tone and content of messages. Codes were then applied to responses independently and an iterative process of in-person discussion was used to reach consensus on any discrepancies. The independent strands of qualitative and quantitative data were collected within the same survey and then analyzed independently and combined to create an overall interpretation of the data, consistent with a convergent parallel mixed methods approach. Qualitative data was analyzed using NVivo qualitative data analysis software; QSR International Pty Ltd. Version 10, 2012 [37].

\section{Results}

A flow chart of how respondents answered questions in the branching logic survey is in Fig. 1.

Invitation fliers were distributed to 1061 adults in the waiting room of the clinic. Of the total sample of nonpregnant females and males over 18 who began the survey $(n=389), 370$ people completed the survey and responded to both questions about speaking to a pregnant woman about smoking and weight gain during pregnancy (Table 1). Of these respondents, $77 \%$ were female, $40 \%$ were non-Hispanic Black and $25 \%$ reported education of high school or less. The average age was 36 years.

Over half of respondents in our community-based sample $(189 / 370 ; 51 \%)$ have spoken to pregnant women regarding either smoking, weight gain in pregnancy, or both. More respondents had spoken to pregnant women about smoking $(40 \%, n=147)$ than weight gain (20\%, $n=73 ; p$-value $<0.001)$ (Table 2$)$. Sixty percent $(223 / 370)$ of participants said they had not spoken to a pregnant woman about smoking during pregnancy. Among those that had not spoken to a woman about smoking during pregnancy, $34 \%$ said they would feel uncomfortable doing so. In contrast, $80 \%$ of people had not spoken to a pregnant woman about weight gain during pregnancy (297/370). Among those who had not spoken 


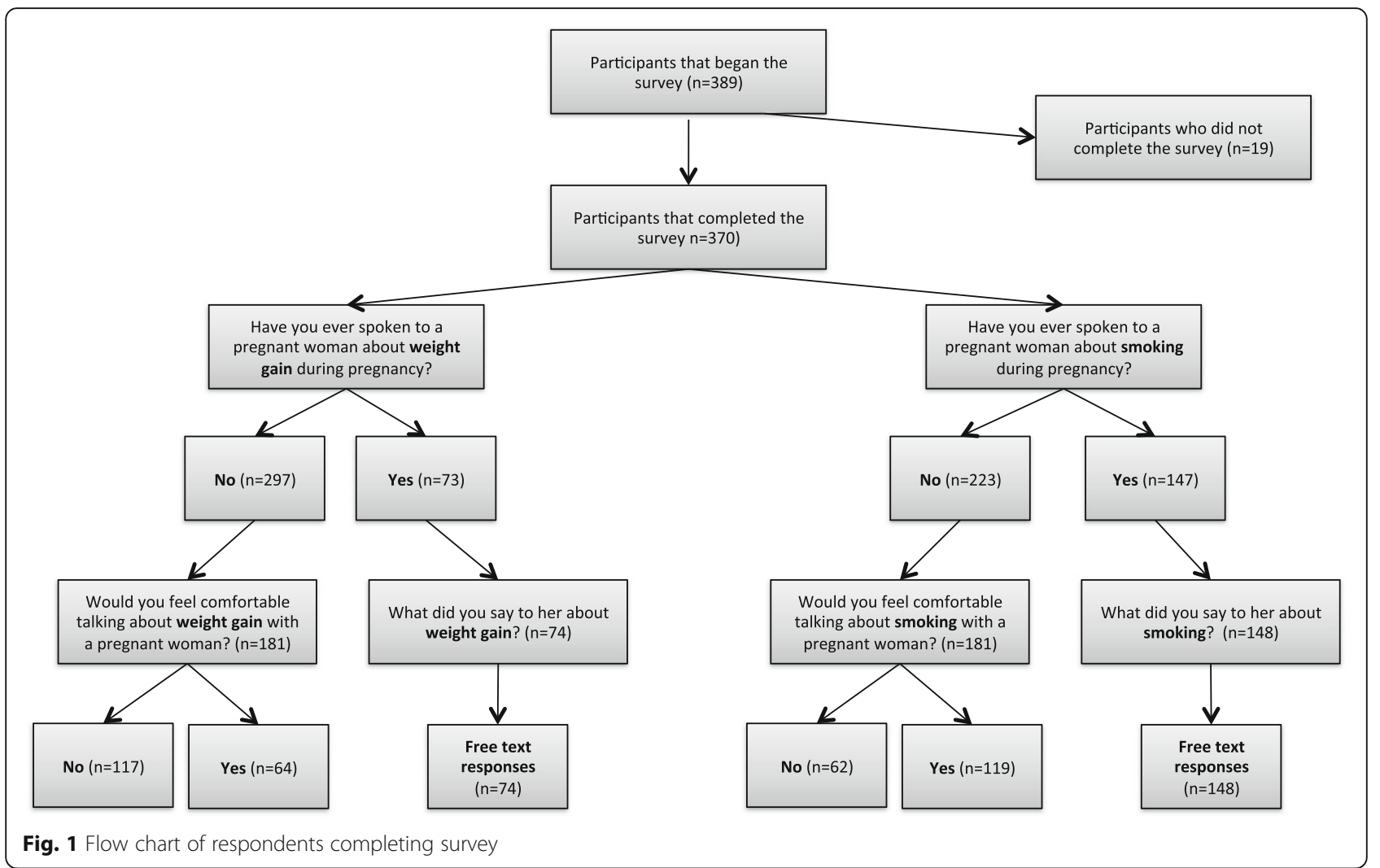

to a woman about weight gain during pregnancy, $65 \%$ said they would feel uncomfortable doing so.

Out of the 181 individuals who did not speak to a pregnant woman about either smoking or weight gain, respondents were more uncomfortable talking about weight gain $(65 \%)$ compared to smoking (34 \%; $p$-value $<0.001)$ (Table 3).

Logistic regression modeling showed that respondents who were female $(\mathrm{OR}=4.77, p$-value $=0.037)$ and of higher education $(\mathrm{OR}=6.21, p$-value $=0.015)$ were more likely to speak to pregnant women about both weight gain and smoking (Table 4). Of the 36 individuals who replied affirmatively to both subjects, the majority were higher educated females $(n=31,86.1 \%)$. Both non-Hispanic black $(\mathrm{OR}=2.94, p$-value $=0.017)$ and "other" race respondents $(\mathrm{OR}=4.54, p$-value $=0.003)$ were more likely to discuss only weight gain with pregnant women when compared to non-Hispanic white respondents. Respondents in the "other" race group (including mixed, Hispanic and Asian) were less likely to talk to pregnant women only about smoking when compared to non-Hispanic white respondents $(\mathrm{OR}=0.43, p$-value $=0.030$; Table 4$)$.

All participants who responded affirmatively to "Have you ever spoken with a pregnant woman about her smoking during pregnancy?" $(n=148)$ responded to "What did you say to her about smoking?" Qualitative analysis revealed that the most common responses were those that recommended abstinence ("Don't do it, stop, quit") ( $n=59)$, and identified smoking as harmful for baby $(n=97)$ or mother $(n=36)$ (Table 5). The most common tone was educational or informational $(n=83)$ followed by directive or imperative $(n=53)$, and occasionally the tone was exaggerated or alarming ("Give your child a chance bc the world is already horrible") $(n=10)$.

All participants who responded affirmatively to "Have you ever spoken with a pregnant woman about her weight gain during pregnancy?" $(n=74)$ responded to "What did you say to her about weight gain?" The most common messages were reassurance ("It's ok if you are gaining weight" or "Eat away") $(n=44)$, warnings against excess weight gain ("Too much was dangerous for her and the baby") $(n=29)$. Other respondents reported discussions with the pregnant woman about weight gain, how much she had gained, and whether or not she was doing certain health behaviors $(n=29)$ (Table 6). The most common tone was normalizing $(n=20)$, followed by educational or informational $(n=18)$, and very few were blaming or judgmental $(n=5)$.

\section{Discussion}

In the setting of increasing rates of obesity among women in the US, there is a particularly pressing need for novel strategies to prevent obesity among women [38]. Our results suggest that respondents in our community- 
Table 1 Demographics of Respondents $\left(N=370^{\mathrm{a}}\right)$

\begin{tabular}{|c|c|}
\hline Variable & \\
\hline Age-mean (SD) & $36.2(12.8)$ \\
\hline \multicolumn{2}{|l|}{ Gender-n (\%) } \\
\hline Female & $283(77)$ \\
\hline Male & $86(23)$ \\
\hline Other & $1(1)$ \\
\hline \multicolumn{2}{|l|}{ Race/Ethnicity-n (\%) } \\
\hline Non-Hispanic Black & $146(40)$ \\
\hline Non-Hispanic White & $168(46)$ \\
\hline Hispanic & $14(4)$ \\
\hline Asian & $14(4)$ \\
\hline Other-Including Mixed & $27(7)$ \\
\hline No Answer (Missing) & 1 \\
\hline \multicolumn{2}{|l|}{ Education-n (\%) } \\
\hline Less than high school & $22(6)$ \\
\hline High school graduate & $70(19)$ \\
\hline Some college & $148(40)$ \\
\hline College graduate or above & $128(35)$ \\
\hline No Answer (Missing) & 2 \\
\hline \multicolumn{2}{|l|}{ Phone type-n (\%) } \\
\hline Smartphone & $317(86)$ \\
\hline Flip-Phone & $8(2)$ \\
\hline Other & $44(12)$ \\
\hline No Answer (Missing) & 1 \\
\hline
\end{tabular}

Percentages may not add to 100 due to rounding

${ }^{\mathrm{a}}$ Excludes the $n=41$ respondents who skipped these questions

based sample were less comfortable addressing weight gain compared to smoking during pregnancy, a welldocumented risk factor for poor maternal and fetal outcomes [2, 3]. This data from community members is consistent with, and adds to, previous studies that demonstrate significant weight stigma and concern for offending pregnant patients among prenatal care providers $[12,14,15,39]$.

Respondents also demonstrated less awareness about the harms of excessive weight gain, and had fewer negatively framed messages for their pregnant peers, compared to smoking. Respondents showed greater understanding of the poor health effects of smoking, had more accurate knowledge about the dangers of smoking ("I asked if she knew the dangers of exposing her unborn child to all the toxins of smoking and the chances of her child having low birth weight or development"), and addressed the issue more directly with pregnant women ("Quitting is the safest and healthiest choice for her and her child"). This reveals that individuals are sharing more varied information about weight gain with pregnant women compared to smoking, suggesting poorer understanding and less comfort in speaking about the harms of excess weight gain compared to smoking.

A potential strategy to prevent the significant morbidity attributable to excess gestational weight gain is to address this common pregnancy risk factor as a public health issue rather than just a clinical issue. Our findings have several important implications. For example, our findings support community-level education (not just to pregnant women) about healthy gestational weight gain as a strategy to change the dialogue and advice surrounding this topic, and increase community members' comfort in talking about it with pregnant women. Additionally, focusing interventions on sub-groups of people more likely to talk to pregnant women about weight gain, including females with some college education, NonHispanic Blacks, and other race groups (Asian, Hispanic, mixed) may prevent the perpetuation of myths.

Responses in our study suggest that friends and family may normalize all weight gain, without discussion of what is healthy. By providing community-wide education, through targeted mass media and social media campaigns, it is possible to spread information quickly and effectively about the Institute of Medicine's guidelines for healthy weight gain during pregnancy [20,40]. Messages that link recommended weight gain to outcomes that are important to patients (i.e. healthy baby, safe delivery) may improve weight management during pregnancy. Additionally, providing resources and education on the specific types of healthy behaviors that promote healthy weight gain is likely important. Interventions that educate pregnant mothers about healthy behaviors during pregnancy have been shown to result in less weight

Table 2 Frequency table of respondents who answered YES or NO to Speaking to Pregnant Women about Smoking or Weight Gain during Pregnancy $(n=370)$

\begin{tabular}{|c|c|c|c|}
\hline \multirow[t]{2}{*}{$\begin{array}{l}\text { "Have you ever spoken to a pregnant woman } \\
\text { about her smoking during pregnancy" }\end{array}$} & \multicolumn{3}{|c|}{$\begin{array}{l}\text { "Have you ever spoken to a pregnant woman about her } \\
\text { weight gain during pregnancy" }\end{array}$} \\
\hline & No & Yes & Total \\
\hline No & 186 & 37 & $223(60 \%)$ \\
\hline Yes & 111 & 36 & $147(40 \%)^{* *}$ \\
\hline Total & 297 (80 \%) & $73(20 \%)^{* *}$ & 370 \\
\hline
\end{tabular}

** $p<0.001$ using McNemar's test 
Table 3 Comparing Respondent Comfort Level when Speaking to Pregnant Women about Smoking versus Weight Gain $\left(N=181^{\mathrm{a}}\right)$

\begin{tabular}{llll}
\multirow{2}{*}{$\begin{array}{l}\text { "Would you feel comfortable talking about } \\
\text { smoking with a pregnant woman" }\end{array}$} & \multicolumn{2}{l}{ "Would you feel comfortable talking about weight } \\
\cline { 2 - 4 } & gain with a pregnant woman" & Yes & Total \\
\hline No & 55 & 7 & $62(34 \%)^{* *}$ \\
Yes & 62 & 57 & $119(66 \%)$ \\
Total & $117(65 \%)^{* *}$ & $64(35 \%)$ & 181 \\
\hline
\end{tabular}

${ }^{\mathrm{a}}$ Five respondents did not answer both questions about comfort

${ }^{* *} p<0.001$ using McNemar's test

gain during pregnancy and higher adherence to Institute of Medicine recommendations for gestational weight gain [41]. Community members could be an important source of accurate knowledge for pregnant women to prevent long-term obesity related to pregnancy weight gain.

Participants in our study also demonstrated varied knowledge as to the specific risks of excessive weight gain. Educational campaigns clearly highlighting the risks of excess weight gain for mother and baby could help women understand the importance of this issue. Previously studied anti-smoking messaging that emphasizes negative outcomes for the baby has improved quit rates for pregnant women $[42,43]$.

Further research is needed on the efficacy of widespread public health messaging for healthy pregnancy weight gain and risks of excess weight gain, including how the topics should be framed, and what core messages should be chosen in order to inform women's weight gain during pregnancy. Intervening during pregnancy has the potential to improve the health of two generations, and to break the cycle of poor health among high-risk populations of women and children [8, 44].

\section{Clinicians and caregivers may need to fill the knowledge gap}

Clinicians and those that provide support and care for pregnant women should acknowledge that friends and family might give inaccurate information about healthy weight gain during pregnancy. As a trusted source of health information, clinicians, nurses, and public health workers should anticipate a knowledge gap about this topic and strive to discuss healthy weight gain with every pregnant woman at every visit $[45,46]$. The frequency of prenatal visits allows for revisiting this topic with opportunities to draw on clinical support resources, such as nurses, nutritional counselors, and social workers, to augment the clinician's efforts. However, these frequent encounters are still less frequent than patients' encounters with their friends and families, highlighting the importance of addressing this issue outside of the clinical

Table 4 Logistic Regression of Demographics on Likelihood of Discussing Smoking and Weight Gain

\begin{tabular}{|c|c|c|c|c|c|c|}
\hline & \multicolumn{2}{|c|}{$\begin{array}{l}\text { YES to "Have you ever spoken to a } \\
\text { pregnant woman about her smoking } \\
\text { during pregnancy" ONLYa }\end{array}$} & \multicolumn{2}{|c|}{$\begin{array}{l}\text { YES to "Have you ever spoken to a pregnant } \\
\text { woman about her weight gain during } \\
\text { pregnancy" ONLY }\end{array}$} & \multicolumn{2}{|c|}{$\begin{array}{l}\text { YES to both previous } \\
\text { questions }\end{array}$} \\
\hline & OR $(95 \% \mathrm{Cl})$ & $p$-value & OR $(95 \%$ Cl) & $p$-value & OR $(95 \%$ Cl) & $p$-value \\
\hline Age in years & $0.99(0.98,1.02)$ & 0.909 & $0.99(0.96,1.02)$ & 0.471 & $0.98(0.96,1.02)$ & 0.419 \\
\hline \multicolumn{7}{|l|}{ Gender $^{d}$} \\
\hline Female & $1.18(0.67,2.05)$ & 0.567 & $0.82(0.37,1.83)$ & 0.625 & $4.77(1.10,20.62)$ & 0.037 \\
\hline Male & Reference & & Reference & & Reference & \\
\hline \multicolumn{7}{|l|}{ Race/Ethnicity } \\
\hline Non-Hispanic White & Reference & & Reference & & Reference & \\
\hline Non-Hispanic Black & $0.72(0.43,1.20)$ & 0.209 & $2.94(1.21,7.11)$ & 0.017 & $1.40(0.64,3.09)$ & 0.399 \\
\hline Other ${ }^{\mathrm{e}}$ & $0.43(0.20,0.92)$ & 0.030 & $4.54(1.68,12.26)$ & 0.003 & $0.78(0.21,2.93)$ & 0.712 \\
\hline \multicolumn{7}{|l|}{ Education } \\
\hline High School or Less & Reference & & Reference & & Reference & \\
\hline Some college and Above & $0.71(0.64,2.05)$ & 0.567 & $0.82(0.38,1.76)$ & 0.611 & $6.21(1.44,26.83)$ & 0.015 \\
\hline
\end{tabular}

${ }^{a}$ Modeling those who said yes to only smoking $(n=111)$ vs. those who said No to discussing smoking $(n=223)$

${ }^{\mathrm{b}}$ Modeling those who said yes to only weight gain $(n=37)$ vs. those who said No to discussing weight gain $(n=297)$

'Modeling those who said yes to both smoking and weight gain $(n=36)$ vs. all others $(n=334)$

"Individual with "other" gender removed from analysis

eIncludes Asian, Hispanic and Mixed 
Table 5 Common themes among people who responded to "What did you say to a pregnant woman about smoking during pregnancy" $(n=148)$

\begin{tabular}{|c|c|}
\hline & Example quotation \\
\hline \multicolumn{2}{|l|}{ Theme } \\
\hline Don't do it, stop, quit $(n=59)$ & $\begin{array}{l}\text { It's best to stop } \\
\text { Don't smoke during pregnancy } \\
\text { She needed to stop asap }\end{array}$ \\
\hline Bad for baby $(N=97)$ & $\begin{array}{l}\text { Think about the baby. Give the baby a fair chance at life. Don't damage the } \\
\text { babies [sic] lungs. } \\
\text { That it can affect your baby's health in a negative way. } \\
\text { That she should stop because I hear the baby can be smaller or premature } \\
\text { That she should stop for her baby and stop being selfish }\end{array}$ \\
\hline Bad for mom $(N=36)$ & $\begin{array}{l}\text { It's not good for you or the baby } \\
\text { She should not do it during pregnancy she has higher risks of preterm delivery } \\
\text { and infections etc. }\end{array}$ \\
\hline It might not be that bad $(N=15)$ & $\begin{array}{l}\text { Advised her to stop, at least while pregnant and/or nursing. } \\
\text { Its okay to smoke but not alot }\end{array}$ \\
\hline Asked questions or had conversation about stopping $(N=13)$ & $\begin{array}{l}\text { That it's not good for the baby when is she going to stop } \\
\text { Is everything OK? I saw you are pregnant. I thought something must be } \\
\text { really wrong if you're smoking and pregnant } \\
\text { Explained the risks it posed, ask if she needed help to quit }\end{array}$ \\
\hline Advice about how to stop smoking $(N=3)$ & $\begin{array}{l}\text { It may } 2 \text { stressful on her child ti quit cild [sic] turkey based } 9 n \text { her amt she } \\
\text { smoked prior } 2 \text { her pregnancy } \\
\text { "tt's bad for the baby to stop cold turkey because the withdrawal" }\end{array}$ \\
\hline You should smoke $(N=2)$ & I was told to take up smoking to lower the birth weight of my child \\
\hline \multicolumn{2}{|l|}{ Tone } \\
\hline Educating or informational (explaining why) $(N=83)$ & $\begin{array}{l}\text { That it was unhealthy for her and the baby } \\
\text { I told her it would probably affect the babies development. } \\
\text { She didn't think it would be harmful, but I pointed out that this was the } \\
\text { greatest form of second hand smoke }\end{array}$ \\
\hline Directive or commanding $(N=53)$ & $\begin{array}{l}\text { It's best to stop } \\
\text { Shouldn't smoke while pregnant }\end{array}$ \\
\hline Encouraging or engaging $(N=18)$ & $\begin{array}{l}\text { Only encouragement to quit } \\
\text { To try to quit smoking, cut down a lot. } \\
\text { I suggested quitting smoking. }\end{array}$ \\
\hline Blaming or judgmental $(N=16)$ & $\begin{array}{l}\text { You shouldn't smoke during pregnancy it will give your baby birth defects. } \\
\text { You want him to have all his toes don't you? } \\
\text { Bad idea. } \\
\text { I said "way to go, now your baby can't breathe fresh air. Yum, I hope she } \\
\text { loves second hand smoke" }\end{array}$ \\
\hline Non committal $(N=11)$ & $\begin{array}{l}\text { It's your choice } \\
\text { Do you smoke more or less? }\end{array}$ \\
\hline Exaggerated or alarming $(N=10)$ & $\begin{array}{l}\text { Your child will come out with a birth defect } \\
\text { Give your child a chance bc the world is already horrible } \\
\text { When you smoke your baby smokes }\end{array}$ \\
\hline
\end{tabular}

setting. Encouraging friends and family to attend prenatal visits may also help with providing a consistent and personalized message about healthy weight gain to pregnant women.

\section{Limitations}

Our findings are subject to certain limitations. Because we used a convenience sample of respondents from one clinic, we are unable to know the demographics and number of people who chose not to participate. We also did not ask participants their occupation or parental status, which may have influenced their responses. As a result, our findings may be biased towards those with higher incomes, higher educational levels, recent parents, or those who are more comfortable using cell phones to text. Though our sample may not be representative, it does reflects the views of a large group of individuals in the waiting room of a low-income primary care clinic. Of note, enough data was collected to reach thematic saturation in our qualitative analysis of the open-ended responses [47, 48]. While significant, some of the predictors of interest in the regression models 
Table 6 Common themes among people who responded to "What did you say to a pregnant woman about weight gain during pregnancy" $(n=74)$

\begin{tabular}{|c|c|}
\hline & Example quotation \\
\hline \multicolumn{2}{|l|}{ Theme } \\
\hline Normalizing weight gain or reassurance $(N=44)$ & $\begin{array}{l}\text { It's a beautiful thing healthy for the baby } \\
\text { I told her it's OK to gain weight } \\
\text { Not to worry about the weight she can lose it } \\
\text { That it doesn't matter how much she gains. }\end{array}$ \\
\hline Warnings about weight gain $(N=29)$ & $\begin{array}{l}\text { It is important to watch your weight because too much or to less can be } \\
\text { harmful to you and the baby } \\
\text { Be cautious with to much weight gain to minimize risk of diabetes, but } \\
\text { too little can deprive the baby of nutrition. } \\
\text { Too much weight gain could lead to gestational diabetes }\end{array}$ \\
\hline Conversation or discussion about weight gain $(N=20)$ & $\begin{array}{l}\text { Just asked how much did she weigh before her pregnancy and how much } \\
\text { did she gain during } \\
\text { How much weight have you gain? Do you eat a lot? } \\
\text { I asked if her gain was normal and how she felt about it } \\
\text { We just discussed it in general. It was a friend who was feeling frustrated } \\
\text { about her doctor's fixation on her weight gain. }\end{array}$ \\
\hline Discussed behavior change $(N=17)$ & $\begin{array}{l}\text { That's it's fine, totally normal, just keep eating healthy and you'll lose it afte } \\
\text { the baby is born. } \\
\text { Watch what she eat and try to exercise a little bit }\end{array}$ \\
\hline Depends on the person or ambivalence $(N=8)$ & $\begin{array}{l}\text { That everyone is different some gain more than others they should eat } \\
\text { healthy drink lots of water and get some exercise } \\
\text { a small to medium amount of weight gain is good in most cases }\end{array}$ \\
\hline Told the amount she should gain $(N=4)$ & $\begin{array}{l}\text { Should gain } 2 \text { _3 lbs per monthly } \\
\text { Gaining around } 30-35 \mathrm{lbs} \text { is normal and healthy }\end{array}$ \\
\hline \multicolumn{2}{|l|}{ Tone } \\
\hline Normalizing or reassurance $(N=20)$ & $\begin{array}{l}\text { Her weight was good } \\
\text { You look great! } \\
\text { That is was normal and that she shouldn't worry }\end{array}$ \\
\hline Educating or informational $(N=18)$ & $\begin{array}{l}\text { Focus on nutrition not cravings } \\
\text { WEIGHT GAIN IS GOOD AND BAD DURING PREGNANCY SO EAT HEALTHY!! }\end{array}$ \\
\hline Encouraging or engaging $(N=18)$ & $\begin{array}{l}\text { It's a beautiful thing healthy for the baby } \\
\text { We talked about what is normal and healthy } \\
\text { We just discussed it in general. It was a friend who was feeling frustrated } \\
\text { about her doctor's fixation on her weight gain. }\end{array}$ \\
\hline Directive or commanding $(N=17)$ & $\begin{array}{l}\text { Don't gain too much } \\
\text { She needed to gain more weight }\end{array}$ \\
\hline Non-committal $(N=12)$ & My wife didn't gain much weight but there wasn't much concern \\
\hline Blaming or judgmental $(N=5)$ & $\begin{array}{l}\text { You need to stop eating the wrong foods } \\
\text { Wow, you are big. }\end{array}$ \\
\hline
\end{tabular}

provided here did have limited distributions leading to wide confidence intervals for effects on the outcomes. Larger sample sizes would lead to more precise estimates of effects. Validity of data collected via text messaging may differ from traditional forms of data collection. However, studies have shown text messaging surveys to be as valid as paper surveys, and that respondents are more likely to be honest and provide higher quality data in text message surveys compared to verbal interviews $[49,50]$. Finally, our research did not explore the limitations experienced by community members in speaking about weight gain during pregnancy, or the accuracy of the advice they provided. These would be potential next steps for research, and further our understanding of the role of community members in promoting healthy weight gain during pregnancy.

\section{Conclusions}

Friends and family are important sources of information in pregnant women's lives. Our study suggests that community members give pregnant women advice during pregnancy, though may be less knowledgeable and comfortable about the harms of excessive weight gain compared to smoking. Though the harms of smoking during pregnancy are clear to community members, the harms of too much weight gain may not be clear. Beyond educating pregnant women, community-level interventions may also be important to ensure that the information pregnant women 
receive supports healthy behaviors and promotes the longterm health of both mothers and babies.

\section{Appendix 1}

\section{Text messaging survey questions}

NOTE: Questions not analyzed in this paper are not presented below.

1. Thank you for taking this survey! It should only take a few minutes. To skip a question, type "skip". To begin, enter the 4 digit code from your info sheet.

2. We'd like to know a little bit about you. What is your age?

3. What is your race/ethnicity?
a. Non-Hispanic BLACK
b. Non-Hispanic WHITE
c. HISPANIC
d. AISAN
e. OTHER race-including Mixed Race

4. What type of phone are you using?
a. Smartphone like Apple iPhone or Samsung Galaxy
b. Flip-phone
c. Other

5. What is the highest level of school you have completed?
a. Less than High School
b. High School Graduate
c. Some College
d. College Graduate or above

6. What is your gender?
a. Male
b. Female
c. Other

7. Are you pregnant now?
a. Yes
b. No
c. Not sure

8. Thanks! The next few questions are about

pregnancy. It doesn't matter if you are male or female. We just want to know your opinion. In your opinion, what is the most important thing a woman should do during pregnancy to have a healthy pregnancy? Please be specific.

9. Have you ever spoken with a pregnant woman about her SMOKING during pregnancy?
a. Yes
b. No

10.What did you say to her about smoking? [Free Text Response]

11. Would you feel comfortable talking about this topic with a pregnant woman?

a. Yes b. No

12.Have you ever spoken with a pregnant woman about her WEIGHT GAIN during pregnancy?

a. Yes

b. No

13. What did you say to her about weight gain during pregnancy? [Free Text Response]

14. Would you feel comfortable talking about this topic with a pregnant woman?

a. Yes

b. No

Acknowledgements

Our study team would like to acknowledge Xiao (Brenda) Xie for her assistance in the statistical analyses.

Funding

University of Michigan Robert Wood Johnson Foundation Clinical Scholars Program.

Availability of data and materials

Data is available upon request from the corresponding author.

\section{Authors' contributions}

TC, BV and LN designed and conducted analyses, prepared the manuscript and approved the final version of the manuscript. MP designed and conducted analyses, prepared the manuscript and approved the final version of the manuscript. MM contributed to study design and prepared and approved the manuscript. MR conceptualized and designed the study, collected data for the study, and approved the final version of the manuscript. All authors certify that the manuscript represents valid work and that neither the submitted manuscript nor one with substantially similar content under their authorship has been published or is being considered for publication elsewhere.

\section{Competing interests}

The authors declare that they have no competing interests.

\section{Consent for publication}

Not applicable.

\section{Ethics approval and consent to participate}

The University of Michigan Institutional Review Board approved reviewed this study and determined that it was exempt from review as all survey data collected was anonymous.

\section{Author details}

${ }^{1}$ Department of Pediatrics, University of North Carolina, 260 MacNider Building CB \#7220, 321 S. Columbia Street, Chapel Hill, NC 27599, USA. ${ }^{2}$ Department of Family Medicine, University of Michigan, 1018 Fuller Street, Ann Arbor, Ml 48104, USA. ${ }^{3}$ Department of Obstetrics \& Gynecology, University of Michigan, 1500 East Medical Center Drive, Ann Arbor, MI 48109, USA. ${ }^{4}$ University of Michigan Medical School, 1301 Catherine Street, Ann Arbor, MI 48109, USA. ${ }^{5}$ Institute for Healthcare Policy and Innovation, University of Michigan, 2800 Plymouth Road, North Campus Research Complex, Building 16, Ann Arbor, MI 48109, USA.

Received: 14 July 2016 Accepted: 1 November 2016 Published online: 09 November 2016

References

1. Deputy NP, Sharma AJ, Kim SY, Hinkle SN. Prevalence and characteristics associated with gestational weight gain adequacy. Obstet Gynecol. 2015; 125:773-81.

2. Jaddoe WW, Troe EJ, Hofman A, Mackenbach JP, Moll HA, Steegers EA Witteman JC. Active and passive maternal smoking during pregnancy and the risks of low birthweight and preterm birth: the Generation R Study. Paediatr Perinat Epidemiol. 2008;22:162-71. 
3. Cnattingius S. The epidemiology of smoking during pregnancy: smoking prevalence, maternal characteristics, and pregnancy outcomes. Nicotine Tob Res. 2004;6 Suppl 2:S125-40.

4. Siega-Riz AM, Viswanathan M, Moos MK, Deierlein A, Mumford S, Knaack J, Thieda P, Lux LJ, Lohr KN. A systematic review of outcomes of maternal weight gain according to the Institute of Medicine recommendations: birthweight, fetal growth, and postpartum weight retention. Am J Obstet Gynecol. 2009;201:339.e1-14.

5. Crane JM, White J, Murphy P, Burrage L, Hutchens D. The effect of gestational weight gain by body mass index on maternal and neonatal outcomes. J Obstet Gynaecol Can. 2009;31:28-35.

6. Rooney BL, Schauberger CW. Excess pregnancy weight gain and long-term obesity: one decade later. Obstet Gynecol. 2002;100:245-52

7. Schmitt NM, Nicholson WK, Schmitt J. The association of pregnancy and the development of obesity-results of a systematic review and meta-analysis on the natural history of postpartum weight retention. Int J Obes (Lond). 2007; 31:1642-51.

8. Olson CM, Strawderman MS, Dennison BA. Maternal weight gain during pregnancy and child weight at age 3 years. Matern Child Health J. 2009;13: 839-46

9. Oken E, Taveras EM, Kleinman KP, Rich-Edwards JW, Gillman MW. Gestational weight gain and child adiposity at age 3 years. Am J Obstet Gynecol. 2007;196:322.e1-8.

10. Ferrari RM, Siega-Riz AM. Provider advice about pregnancy weight gain and adequacy of weight gain. Matern Child Health J. 2013;17:256-64.

11. Herring SJ, Henry TQ, Klotz AA, Foster GD, Whitaker RC. Perceptions of lowincome African-American mothers about excessive gestational weight gain. Matern Child Health J. 2012;16:1837-43.

12. Stengel MR, Kraschnewski $J$, Hwang SW, Kjerulff $\mathrm{KH}$, Chuang $\mathrm{CH}$. "What my doctor didn't tell me": examining health care provider advice to overweight and obese pregnant women on gestational weight gain and physical activity. Womens Health Issues. 2012;22:e535-40.

13. Phelan S, Phipps MG, Abrams B, Darroch F, Schaffner A, Wing RR. Practitioner advice and gestational weight gain. J Womens Health (Larchmt). 2011;20:585-91.

14. Chang T, Llanes M, Gold KJ, Fetters MD. Perspectives about and approaches to weight gain in pregnancy: a qualitative study of physicians and nurse midwives. BMC Pregnancy Childbirth. 2013;13:47

15. Cabana MD, Rand CS, Powe NR, Wu AW, Wilson MH, Abboud PA, Rubin HR. Why don't physicians follow clinical practice guidelines? A framework for improvement. JAMA. 1999;282:1458-65.

16. Declercq ER, Sakala C, Corry MP, Applebaum S. Listening to Mothers II: Report of the Second National U.S. Survey of Women's Childbearing Experiences: Conducted January-February 2006 for Childbirth Connection by Harris Interactive(R) in partnership with Lamaze International. J Perinat Educ. 2007;16:9-14.

17. Larsson M. A descriptive study of the use of the Internet by women seeking pregnancy-related information. Midwifery. 2009;25:14-20.

18. Huberty J, Dinkel D, Beets MW, Coleman J. Describing the use of the internet for health, physical activity, and nutrition information in pregnant women. Matern Child Health J. 2013;17:1363-72.

19. Chang T, Verma BA, Shull T, Moniz MH, Kohatsu L, Plegue MA, Collins-Thompson K. Crowdsourcing and the accuracy of online information regarding weight gain in pregnancy: a descriptive study. J Med Internet Res. 2016;18:e81.

20. Rasmussen KM, Yaktine AL, Institute of Medicine (U.S.). Committee to Reexamine IOM Pregnancy Weight Guidelines. In: Weight gain during pregnancy: reexamining the guidelines. Washington, DC: National Academies Press; 2010.

21. Brownfoot FC, Davey MA, Kornman L. Women's opinions on being weighed at routine antenatal visits. BJOG. 2016:123:263-70.

22. Tovar A, Chasan-Taber L, Bermudez OI, Hyatt RR, Must A. Knowledge, attitudes, and beliefs regarding weight gain during pregnancy among Hispanic women. Matern Child Health J. 2010;14:938-49.

23. Glanz K, Rimer BK, Viswanath K. Health behavior and health education: theory, research, and practice. San Francisco: Wiley; 2008.

24. Hodnett ED, Gates S, Hofmeyr GJ, Sakala C, Weston J. Continuous support for women during childbirth. Cochrane Database Syst Rev. 2011;2: CD003766.

25. Whitaker KM, Wilcox S, Liu J, Blair SN, Pate RR. African American and White womens perceptions of weight gain, physical activity, and nutrition during pregnancy. Midwifery. 2016;34:211-20.
26. Groth SW, Morrison-Beedy D, Meng Y. How pregnant African American women view pregnancy weight gain. J Obstet Gynecol Neonatal Nurs. 2012:41:798-808.

27. Clarke PE, Gross H. Women's behaviour, beliefs and information sources about physical exercise in pregnancy. Midwifery. 2004:20:133-41.

28. Szwajcer EM, Hiddink GJ, Koelen MA, van Woerkum CM. Nutrition-related information-seeking behaviours before and throughout the course of pregnancy: consequences for nutrition communication. Eur J Clin Nutr. 2005;59 Suppl 1:S57-65.

29. Pederson LL. Compliance with physician advice to quit smoking: a review of the literature. Prev Med. 1982;11:71-84.

30. Dunn $\mathrm{CL}$, Pirie $\mathrm{PL}$, Hellerstedt WL. The advice-giving role of female friends and relatives during pregnancy. Health Educ Res. 2003;18:352-62.

31. Chamberlain C, O'Mara-Eves A, Oliver S, Caird JR, Perlen SM, Eades SJ, Thomas J. Psychosocial interventions for supporting women to stop smoking in pregnancy. Cochrane Database Syst Rev. 2013;10:CD001055.

32. Bayer R, Stuber J. Tobacco control, stigma, and public health: rethinking the relations. Am J Public Health. 2006;96:47-50.

33. Bull L, Burke R, Walsh S, Whitehead E. Social attitudes towards smoking in pregnancy in East Surrey: a qualitative study of smokers, former smokers and non-smokers. J Neonatal Nurs. 2007;13:100-6.

34. Chapman S, Freeman B. Markers of the denormalisation of smoking and the tobacco industry. Tob Control. 2008;17:25-31.

35. Chang T, Gossa W, Sharp A, Rowe Z, Kohatsu L, Cobb EM, Heisler M. Text messaging as a community-based survey tool: a pilot study. BMC Public Health. 2014;14:936.

36. Pew Research Center. Mobile technology fact sheet. 2013. http://www. pewinternet.org/fact-sheets/mobile-technology-fact-sheet/ . Accessed 5 Nov 2016.

37. Creswell JW. Research design: Qualitative, quantitative, and mixed methods approaches. Thousand Oaks: Sage publications; 2013.

38. Flegal KM, Kruszon-Moran D, Carroll MD, Fryar CD, Ogden CL. Trends in obesity among adults in the United States, 2005 to 2014. JAMA. 2016;315:2284-91.

39. Mulherin K, Miller YD, Barlow FK, Diedrichs PC, Thompson R. Weight stigma in maternity care: women's experiences and care providers' attitudes. BMC Pregnancy Childbirth. 2013;13:19.

40. Grier S, Bryant CA. Social marketing in public health. Annu Rev Public Health. 2005:26:319-39.

41. Skouteris H, Hartley-Clark L, McCabe M, Milgrom J, Kent B, Herring SJ, Gale J. Preventing excessive gestational weight gain: a systematic review of interventions. Obes Rev. 2010;11:757-68.

42. Fingerhut LA, Kleinman JC, Kendrick JS. Smoking before, during, and after pregnancy. Am J Public Health. 1990;80:541-4.

43. Ershoff DH, Quinn VP, Boyd NR, Stern J, Gregory M, Wirtschafter D. The Kaiser Permanente prenatal smoking-cessation trial: when more isn't better, what is enough? Am J Prev Med. 1999;17:161-8.

44. Poston L. Maternal obesity, gestational weight gain and diet as determinants of offspring long term health. Best Pract Res Clin Endocrinol Metab. 2012;26:627-39.

45. Hesse BW, Nelson DE, Kreps GL, Croyle RT, Arora NK, Rimer BK, Viswanath K. Trust and sources of health information: the impact of the Internet and its implications for health care providers: findings from the first Health Information National Trends Survey. Arch Intern Med. 2005;165:2618-24.

46. Ferrari RM, Siega-Riz AM, Evenson KR, Moos MK, Carrier KS. A qualitative study of women's perceptions of provider advice about diet and physical activity during pregnancy. Patient Educ Couns. 2013;91:372-7.

47. Guest G, Bunce A, Johnson L. How many interviews are enough? An experiment with data saturation and variability. Field Methods. 2006;18:59-82.

48. Ando $H$, Cousins R, Young C. Achieving saturation in thematic analysis: Development and refinement of a codebook. Compr Psychol. 2014:3:03.CP.3.4

49. Keding A, Bohnke JR, Croudace TJ, Richmond SJ, MacPherson H. Validity of single item responses to short message service texts to monitor depression: an mHealth sub-study of the UK ACUDep trial. BMC Med Res Methodol. 2015;15:56.

50. Schober MF, Conrad FG, Antoun C, Ehlen P, Fail S, Hupp AL, Johnston M, Vickers L, Yan HY, Zhang C. Precision and disclosure in text and voice interviews on smartphones. PLoS One. 2015:10:e0128337. 